\title{
Morphology of ettringite crystal of sulfoferrite clinker
}

\author{
Dmitriy Zorin ${ }^{1, *}$ and Ivan Burlov ${ }^{2}$ \\ ${ }^{1}$ The Moscow State University of Civil Engineering (National Rresearch University), Yaroslavskoye \\ shosse, 26, 125993, Moscow, Russia \\ ${ }^{2}$ Mendeleev University of Chemical Technology, Miusskaya square, 9, 125047, Moscow, Russia
}

\begin{abstract}
This paper deals with the composition and properties of solid solution of calcium sulfoferrite. It was studied an influence of calcium $\mathrm{s}$ sulfoferrite on structure and properties cement phases. Study of the hydration processes of the calcium sulfoferrite mineral are observed only short prismatic crystals. Prismatic crystals of ferruginous ettringite are always formed from sulfoferrite mineral of any fraction. it was found that the smaller the initial hydrating grains of minerals, the faster they are hydrated. Analyse polyfractional compound hydration showed that fine fractions provide formation of crystallization centres, and particles less than 45 microns, with constant interaction with the liquid phase, cause a gradual growth of crystals. Expansion of hydrated minerals of certain fractions was analysed to check the dependence of the expansion on the morphology of ettringite crystal hydrates. During the hardening of the samples, expansion was observed along with a drop in strength.
\end{abstract}

\section{Introduction}

Hydration and hardening of Portland cement are accompanied by generating of crystalline and gel-like products, which, together with non-hydrated grains, participate in formation of the three-dimensional framework of the cement stone[1-3].

Depending on activity of the original mineral, the crystalline hydrates are formed sequentially or simultaneously, while they filling the free space in the cement stone. Then, the crystalline hydrates bind to the cement stone framework by accretion, and gel-like hydration products compact it.

Various studies have shown that concentration of the liquid phase reaches a certain limiting value, at which the primary nuclei of new phases appear resulted from dissolution of minerals.

Probability of nucleation from supersaturated solutions and rate of formation of crystallization centres proportional to it in solution volume unit per time unit are directly proportional to the degree of supersaturation of the solution with respect to the new phase.

As you know, supersaturation of the liquid phase depends on dispersion of the hydrating component, and the dispersion, in turn, affects morphology and amount of formed hydrates and is the driving force behind formation and growth of crystals formed from the solution.

\footnotetext{
* Corresponding author: dim-z@yandex.ru
} 
Ettringite is the main crystalline hydrate involved in expansion of the cement stone [45]. However, as shown in [6], ettringite crystal hydrates have different morphologies, and, therefore, not all crystals cause the effect of system expansion. The study of ettringite morphology is important for describing the hardening of expanding cements [7-13]. One of these additives is sulfoferrite clinker [14-15].

\section{Materials and methods}

The research of the effect of dispersion of expanding component on the morphology of the formed ettringite was carried out with the mineral of $\mathrm{C} 2.8 \mathrm{~F} \bar{S} 0.8$ sulfoferrite clinker.

Mineralogical composition of cements is presented in table 1. Physical properties and chemical analysis of clinkers are shown in table 2.

Table 1. Mineralogical composition of cements.

\begin{tabular}{|l|l|l|}
\hline & OPC & SAFC \\
\hline Alite & 67 & 12 \\
\hline Belite & 8 & 30 \\
\hline Tricalcium aluminate & 5 & - \\
\hline Calcium aluminoferrite & 13 & 58 \\
\hline Calcium sulfoferrite & - & - \\
\hline
\end{tabular}

Table 2. Physical and chemical properties of cements and sulfoferrite clinker.

\begin{tabular}{|c|c|c|}
\hline & OPC & SFC \\
\hline Specific gravity & 3.16 & 2.96 \\
\hline Blaine fineness, $\mathrm{cm}^{2} / \mathrm{g}$ & $2700(3500)$ & 4230 \\
\hline Loss of ignition, \% & 0.21 & 0.01 \\
\hline $\mathrm{SiO}_{2}, \%$ & 22.03 & 12.23 \\
\hline $\mathrm{Al}_{2} \mathrm{O}_{3}, \%$ & 5.15 & 3.09 \\
\hline $\mathrm{CaO}, \%$ & 65.41 & 51.83 \\
\hline $\mathrm{MgO}, \%$ & 1.20 & 1.92 \\
\hline $\mathrm{SO}_{3}, \%$ & 0.34 & 5.19 \\
\hline $\mathrm{Fe}_{2} \mathrm{O}_{3}, \%$ & 4.86 & 23.79 \\
\hline
\end{tabular}

To do so, it was ground to fractions $>80 \mu \mathrm{m}, 63-80,45-63,28-45$ and less than $28 \mu \mathrm{m}$. The samples were mixed with a saturated gypsum solution (to exclude gypsum dispersion), after which they have been hardened for 6, 12 and 24 hours, as well as for 3, 7, 14 and 28 days.

The samples were analysed by various physicochemical methods. Amount of ferruginous ettringite formed was determined by the chemical method [6].

\section{Results}

The results of the research of the sulfoferrite mineral proved that the smaller the initial hydrating grains of minerals, the faster they are hydrated.

Calcium sulfoferrite $\mathrm{C} 2.8 \mathrm{~F} \bar{S} 0.8$ hydrates rather slowly.

Slow $\mathrm{pH}$ growth rate indicates slow saturation of the liquid phase with calcium ions. The maximum $\mathrm{pH}=13$ has achieved with hydration of the fraction less than 28 microns after 24 hours. A larger number of formed crystals is recorded in the same fraction, at the same time (Figure 1). 
Table 3. The characteristic of the process of $2 \mathrm{CaOFe} 2 \mathrm{O} 30.8 \mathrm{CaSO} 4$ mineral hydration for different fractions.

\begin{tabular}{|c|c|c|c|}
\hline $\begin{array}{c}\text { Grain size, } \\
\boldsymbol{\mu} \mathbf{m}\end{array}$ & $\begin{array}{c}\text { Time of hydration, } \\
\text { days }\end{array}$ & $\begin{array}{c}\text { Degree of hydration } \\
\text { (X-ray), \% }\end{array}$ & $\begin{array}{c}\text { Amount of ferrous } \\
\text { ettringite }\end{array}$ \\
\hline \hline \multirow{4}{*}{$<28$} & 0.25 & 12.3 & 14.8 \\
\cline { 2 - 4 } & 0.5 & 23.2 & 25.3 \\
\cline { 2 - 4 } & 1 & 26.8 & 28.2 \\
\hline \multirow{4}{*}{$28-45$} & 3 & 29.8 & 36.9 \\
\cline { 2 - 4 } & 0.25 & 11.6 & 13.5 \\
\cline { 2 - 4 } & 0.5 & 21.6 & 23.9 \\
\cline { 2 - 4 } & 1 & 25.6 & 29.5 \\
\hline \multirow{4}{*}{$45-63$} & 3 & 28.8 & 36.1 \\
\cline { 2 - 4 } & 0.5 & 18.4 & 13.1 \\
\cline { 2 - 4 } & 1 & 21.3 & 24.1 \\
\hline \multirow{4}{*}{$63-80$} & 3 & 30.5 & 37.3 \\
\cline { 2 - 4 } & 0.5 & 14.8 & 11.5 \\
\cline { 2 - 4 } & 1 & 18.9 & 12.5 \\
\hline \multirow{4}{*}{$>80$} & 3 & 24.2 & 32.2 \\
\cline { 2 - 4 } & 7 & 30.8 & 37.7 \\
\cline { 2 - 4 } & 1 & 7.1 & 7.7 \\
\cline { 2 - 4 } & 3 & 8.3 & 9.2 \\
\cline { 2 - 4 } & 14 & 15.0 & 12.9 \\
\hline
\end{tabular}

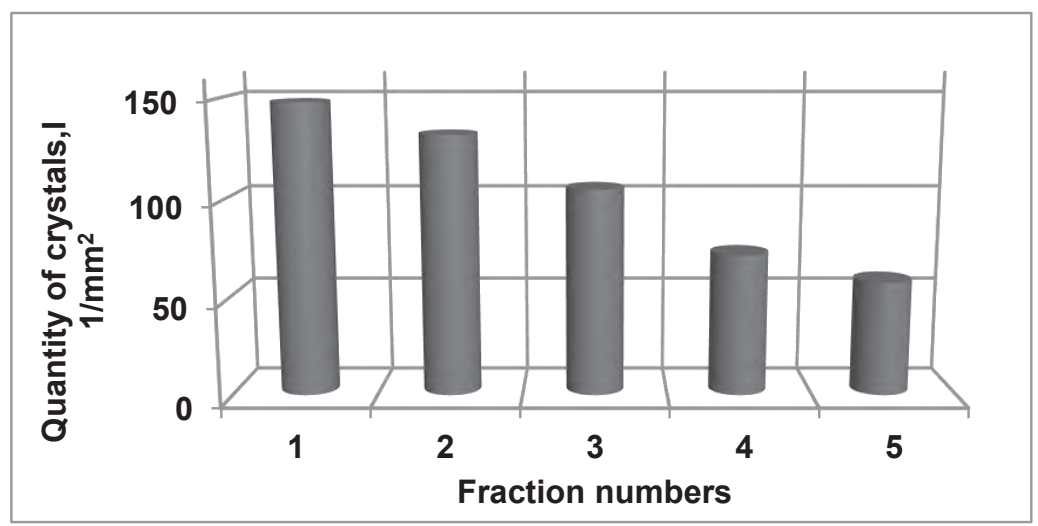

Fig. 1. Initially formed crystals per $1 \mathrm{~mm} 2$ of microscope slide for hydration within 24 hours of $2 \mathrm{CaOFe} 2 \mathrm{O} 30.8 \mathrm{CaSO} 4$ different fractions $(1$ - fractions less than $28 \mu \mathrm{m} ; 2-28-45 \mu \mathrm{m} ; 3-45-63 \mu \mathrm{m}$; $4-63-80 \mu \mathrm{m} ; 5->80 \mu \mathrm{m})$.

Prismatic crystals of ferruginous ettringite are always formed from $\mathrm{C} 2.8 \mathrm{~F} \bar{S} 0.8$ mineral of any fraction.

It is clear that it is rather difficult to get monofractional compositions under production conditions. Therefore, researches were carried out on influence of the polyfraction composition of $\mathrm{C} 2.8 \mathrm{~F} \bar{S} 0.8$ minerals on the morphology of crystals of the ettringite formed.

The polydiffraction formulations of minerals were prepared by mixing fine and coarse fractions in a 1:1 ratio.
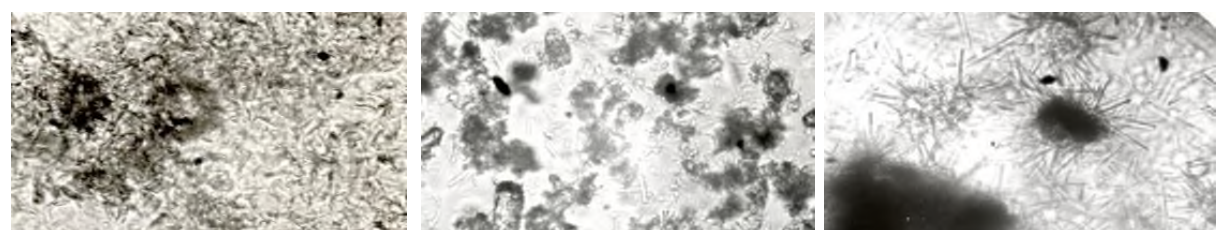
a

b

c

Fig. 2. Crystallization of ettringite during hydration of the mineral $\mathrm{C}_{2.8} \mathrm{~F} \bar{S}_{0.8}$ various factions ( a fraction $28-40 \mu \mathrm{m}, 24$ hours, $\mathrm{b}$ - fraction $45-63 \mu \mathrm{m}, 3$ days, $\mathrm{c}$ - fraction $>80 \mu \mathrm{m}, 3$ days).

For minerals $\mathrm{C}_{2.8} \mathrm{~F} \bar{S}_{0.8}$, fractions less than 28 microns and a fraction of $28-45$ microns were chosen, since these fractions are the most intensively hydrated in the first 24 hours.

Composition of the liquid phase and amount of ettringite were determined by the chemical method. Table 4 includes the results.

Table 4. The amount of formed ettringite during hydration polyfractional compositions of minerals.

\begin{tabular}{|c|c|c|c|c|}
\hline Mineral & $\begin{array}{c}\text { Time of } \\
\text { hydration, } \\
\text { days }\end{array}$ & $\begin{array}{c}\text { Amount of } \\
\text { ferrous } \\
\text { ettringite }\end{array}$ & $\begin{array}{c}\text { Habitus of } \\
\text { crystal (d/l) }\end{array}$ & $\begin{array}{c}\text { Morphology of } \\
\text { crystal }\end{array}$ \\
\hline \multirow{3}{*}{$\mathrm{C}_{2.8} \mathrm{~F} \overline{\mathrm{S}}_{0.8}$} & 0.25 & 13.3 & - & - \\
\cline { 2 - 5 } & 0.5 & 26.1 & - & Short prismatic \\
\cline { 2 - 5 } & 1 & 30.3 & 0.2288 & \multicolumn{2}{|c}{} \\
\hline
\end{tabular}

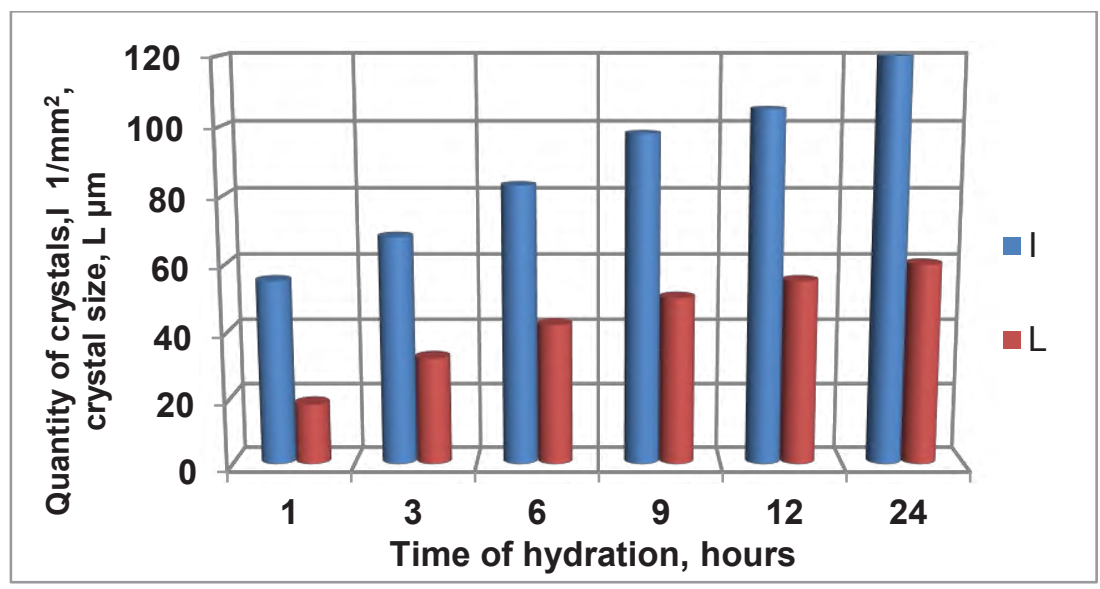

Fig. 3. Medium $\mathrm{pH}$ variation of the liquid phase during hydration, initially formed crystals per $1 \mathrm{~mm}^{2}$ of microscope slide for hydration within 24 hours and crystal size.

As is known, generating of fine-crystalline ettringite contributes to compaction and growth of strength of the cement stone, and formation of large prismatic or needle-like crystals causes expansion of the system.

Expansion of hydrated minerals of certain fractions was analysed to check the dependence of the expansion on the morphology of ettringite crystal hydrates. Fractions of 28-40 microns were taken for calcium sulfoferite mineral, since these fractions are most intensively hydrated. Table 5 includes characteristics of the morphology of ettringite crystals. 
Table 5. Morphology of ettringite crystals.

\begin{tabular}{|c|c|c|c|}
\hline .Mineral & Fraction $(\mu \mathrm{m})$ & $\begin{array}{c}\text { Habitus of } \\
\text { crystal }(\mathrm{d} / \mathrm{l})\end{array}$ & $\begin{array}{c}\text { Morphology of } \\
\text { crystal }\end{array}$ \\
\hline $\mathrm{C}_{2.8} \mathrm{~F} \overline{\mathrm{S}}_{0.8}$ & $28-40$ & 0.2308 & Short prismatic \\
\hline
\end{tabular}

A dough was kneaded with a ratio of 0.3 from powders of minerals of fractions 28-40 $\mu \mathrm{m}$ and a saturated gypsum solution. The dough was formed into beams for the expansion tests and cubes for the compression tests. The samples were hardened in water conditions and were tested after a certain time. Figures 4 and 5 includes the test results.

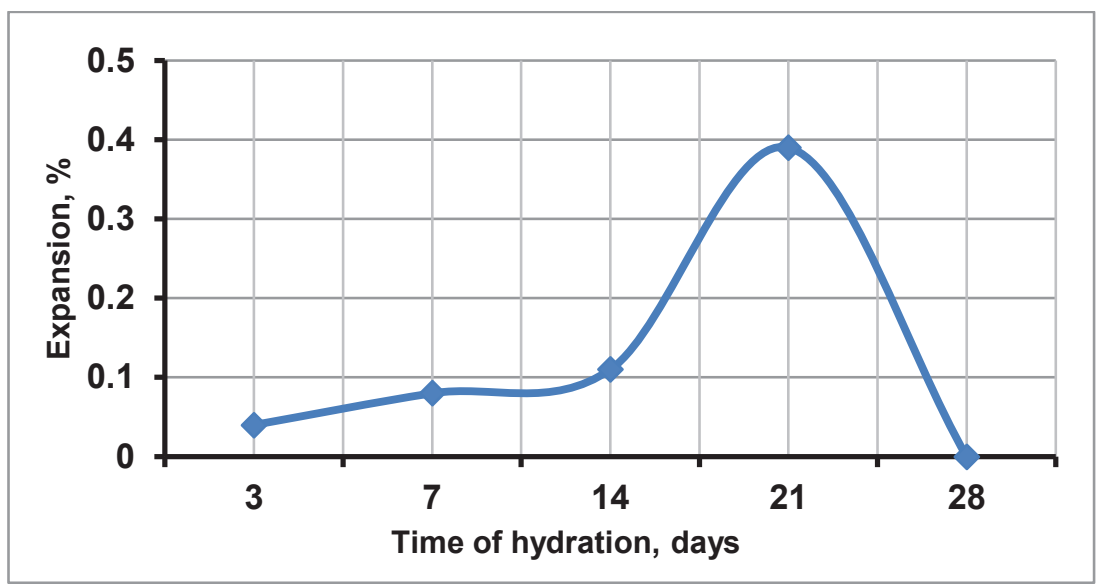

Fig. 4. Expansion of cement.

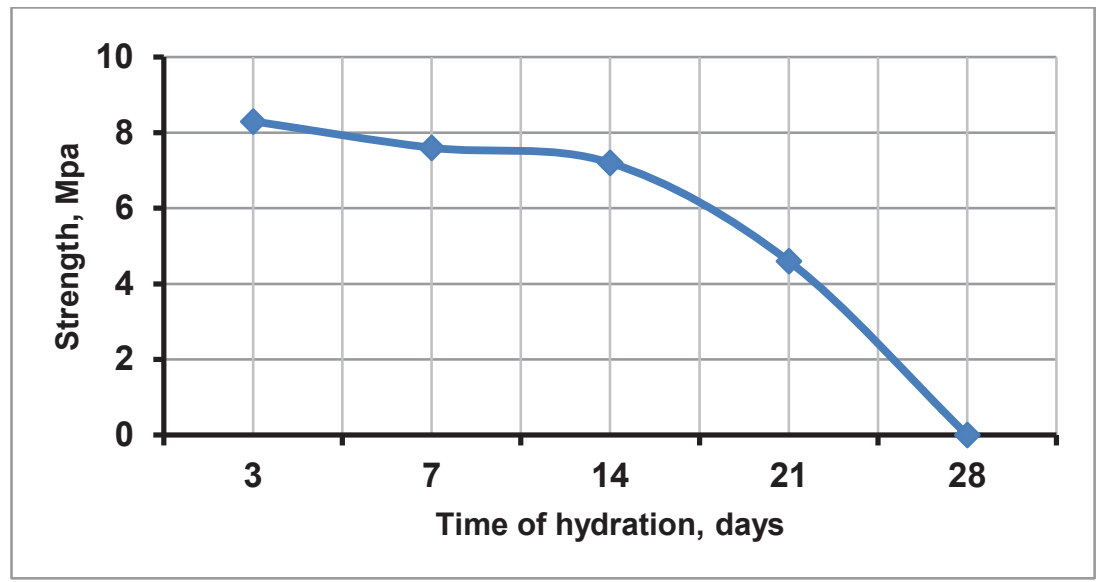

Fig. 5. Strength of cements.

\section{Discussion}

It is established that the smaller the initial hydrating grains of minerals, the faster they are hydrated. This shows an increase in the degree of hydration according to the data of X-ray phase analysis, as well as according to the data of chemical analysis, while more ettringite crystals are formed (Table 3 ). 
When hydrating calcium sulfoferrite mineral of $\mathrm{C}_{2.8} \mathrm{~F} \bar{S}_{0.8}$ formulation, only short prismatic crystals are observed $(l=50-60$ microns, $d=5-6$ microns $)$, and in small fractions (28-45 and less than 28 microns) such crystals begin to form around the original grains of the mineral after 24 hours, in fractions 45-63 - at the age of 3 days, and in large fractions (63-80 and $>80 \mu \mathrm{m})$ only by 14 days (Fig. 2 ).

In comparison with monofraction compositions (Table 3), the amount of ettringite in the first hours and days of hydration is somewhat lower than in fine fractions, but higher than in large fractions.

Analyse of $\mathrm{C}_{2.8} \mathrm{~F} \bar{S}_{0.8}$ polyfractional compound hydration showed that fine fractions provide formation of crystallization centres, and particles less than 45 microns, with constant interaction with the liquid phase, cause a gradual growth of crystals (Fig. 3).

During the hardening of the samples, expansion was observed along with a drop in strength. Upon reaching 21 and 28 days, the samples were covered with cracks and destroyed. This is due to the increased rate of expansion compared to the rate of formation of the solid cementitious framework (Fig. 4 and 5).

\section{Conclusions}

The research carried out allows us to conclude that a polyfractional compound is preferable for expanding of calcium sulfoferrite-based additives, which combines only small fractions $(<28 \mu \mathrm{m}$ and $28-45 \mu \mathrm{m})$.

When hydrating $\mathrm{C}_{2.8} \mathrm{~F} \bar{S}_{0.8}$, only formation of prismatic crystals of ferruginous ettringite occurs and their formation depends on the mineral hydration rate, which increases with increasing dispersion to the size of fractions $28-45$ microns and $<28$ microns. Samples from this mineral have a slight expansion, but with low strength, it is enough to destroy the samples.

According to the results of the research, it can be concluded that by changing the fractional composition of the expanding component in the composition of the composite binder, conditions for formation of ettringite crystals of various morphologies and different amounts can be created. This makes it possible to get various types of special cements.

\section{References}

1. K. Liu, A. Chen, X. Shang, et.al., The impact of mechanical grinding on calcium aluminate cement hydration at $30^{\circ} \mathrm{C}$, Ceramics International 45, 11, 14121-14125 (2019) https://doi.org/10.1016/j.ceramint.2019.04.112

2. G. Huang, D. Pudasainee, R. Gupta, W.V. Liu, Hydration reaction and strength development of calcium sulfoaluminate cement-based mortar cured at cold temperatures, Construction and Building Materials 224, 493-503 (2019) https://doi.org/10.1016/j.conbuildmat.2019.07.085

3. N. Duc Van, H. Choi, Y. Hama, Modeling early age hydration reaction and predicting compressive strength of cement paste mixed with expansive additives, Construction and Building Materials 223, 994-1007 https://doi.org/10.1016/j.conbuildmat.2019.07.290

4. J. Zhang, G. Li, W. Ye, Y. Chang, Q. Liu, Z. Song, Effects of ordinary Portland cement on the early properties and hydration of calcium sulfoaluminate cement, Construction and Building Materials 186, 1144-1153 (2018) https://doi.org/10.1016/j.conbuildmat.2018.08.008 
5. L. Xu P. Wang G. Zhang, Formation of ettringite in Portland cement/calcium aluminate cement/calcium sulfate ternary system hydrates at lower temperatures, Construction and Building Materials 31, 347-352 (2012) https://doi.org/10.1016/j.conbuildmat.2011.12.078

6. S.V. Samchenko, Y.R. Krivoborodov, The increase of hydration activity of portland cement by additives of crystalline hydrates, Materials Science Forum 974, 195-200 (2019) DOI: 10.4028/www.scientific.net/msf.974.195

7. J. Bizzozero, Ch. Gosselin, K. L. Scrivener, Expansion mechanisms in calcium aluminate and sulfoaluminate systems with calcium sulfate, Cement and Concrete Research 56, 190-202 (2014) https://doi.org/10.1016/j.cemconres.2013.11.011

8. I.N. Borisov, O.S. Mandrikova, D.A. Mishin, I.A. Morozova, S.V. Kovalev, Features of formation of the phase composition and structure sulfoferrite clinker based onsulfate containing secondary raw, Advances in Environmental Biology 8(13), 139-144 (2014) http://www.aensiweb.net/AENSIWEB/aeb/aeb_August_2014.html

9. R. Moradpour, E. Taheri-Nassaj, T. Parhizkar, M. Ghodsian, The effects of nanoscale expansive agents on the mechanical properties of non-shrink cement-based composites: The influence of nano- $\mathrm{MgO}$ addition, Composites Part $\mathrm{B}$ : Engineering 55, 193-202 (2013) https://doi.org/10.1016/j.compositesb.2013.06.033

10. Zh. Liu, W. Hansen, Construction and Building Materials 121, 429-436 (2016) https://doi.org/10.1016/j.conbuildmat.2016.06.012

11. Y. Krivoborodov, E. Potapova, S. Samchenko, T. Kouznetsova, The use of sulphate waste for modifying cement clinkers, International Multidisciplinary Scientific GeoConference Surveying Geology and Mining Ecology Management, SGEM 19(6.2), 303-308 (2019) DOI: 10.5593/sgem2019/6.2

12. R. Gagné, Expansive agents, Science and Technology of Concrete Admixtures (University of Sherbrooke, QC, Canada, 2016) https://doi.org/10.1016/B978-0-08100693-1.00022-9

13. S. Monosi, R. Troli, O. Favoni, F. Tittarelli, Effect of SRA on the expansive behaviour of mortars based on sulphoaluminate agent, Cement and Concrete Composites 33, 4 (2011) ttps://doi.org/10.1016/j.cemconcomp.2011.01.001

14. Yu.R. Krivoborodov, S.V. Samchenko, T.V. Kuznetsova, Structural Changes in Refractory Calcium Aluminate Cement Concrete, Refractories and Industrial Ceramics 59, 151-155 (2018) DOI: 10.1007/s11148-018-0197-1

15. S.V. Samchenko, Y.R. Krivoborodov, Synthesis of high alumina cement based on metallurgy wastes, IOP Conference Series: Materials Science and Engineering 687(2), 022034 (2019) DOI: 10.1088/1757-899X/687/2/022034 